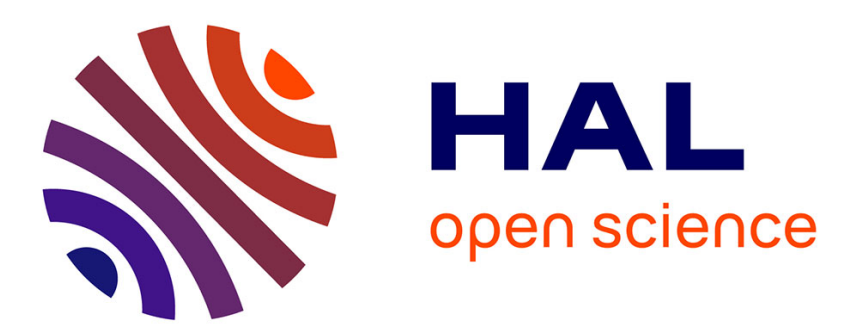

\title{
A Model for Strengthening the Software Engineering Research Capacity
}

Roumen Nikolov, Sylvia Ilieva

\section{To cite this version:}

Roumen Nikolov, Sylvia Ilieva. A Model for Strengthening the Software Engineering Research Capacity. SEESE Workshop on ICSE 2008, 2008, Germany. pp.1. hal-00592700

\section{HAL Id: hal-00592700 https://hal.science/hal-00592700}

Submitted on 13 May 2011

HAL is a multi-disciplinary open access archive for the deposit and dissemination of scientific research documents, whether they are published or not. The documents may come from teaching and research institutions in France or abroad, or from public or private research centers.
L'archive ouverte pluridisciplinaire HAL, est destinée au dépôt et à la diffusion de documents scientifiques de niveau recherche, publiés ou non, émanant des établissements d'enseignement et de recherche français ou étrangers, des laboratoires publics ou privés. 


\section{A Model for Strengthening the Software Engineering Research Capacity}

\author{
Roumen Nikolov \\ FMI - Sofia University \\ 5, J. Bourchier str., P.B. 48 \\ Sofia 1164, Bulgaria \\ roumen@fmi.uni-sofia.bg \\ http://www-it.fmi.uni-sofia.bg/
}

\author{
Sylvia Ilieva \\ FMI - Sofia University \\ 5, J. Bourchier str., P.B. 48 \\ Sofia 1164, Bulgaria \\ sylvia@fmi.uni-sofia.bg \\ http://www-it.fmi.uni-sofia.bg/
}

\begin{abstract}
Like all other New Member States (NMS) Bulgaria is experiencing a dramatic change in all areas of its society. These changes reflect very seriously on the research capacity of the country and, in particular to Sofia University (SU). The Faculty of Mathematics and Informatics (FMI) has experienced some serious problems closely related to the general socio-economic and the research environment in Bulgaria. This paper describes a model for strengthening the research capacity of FMI, especially the one in the area of Software Engineering. The case study of successful industry-university cooperation in the framework of European project is presented.
\end{abstract}

\section{Keywords}

Software engineering research, models for strengthening university research capacity, industry university cooperation

\section{INTRODUCTION}

Like all other New Member States (NMS) Bulgaria is experiencing a dramatic change in all areas of its society. These changes reflect very seriously on the research capacity of the country and, in particular to Sofia University (SU). The Faculty of Mathematics and Informatics (FMI) has experienced some serious problems closely related to the general socio-economic and the research environment in Bulgaria:

- Emigration and migration to industry of highly skilled professionals. During the last 15 years more than 50 researchers from FMI left the university to join leading European and American companies.

- Insufficient research funding. The loss of many experienced researchers decreases the chances and capacity for contractual research. The income from R\&D contracts with Ministry of Education and Science (MES) and industry has declined dramatically since 1989.

- Lack of sufficiently stimulating research environment. Bulgaria is still in a process of transition from a model, which separates research (done mainly at the Academy of Sciences) from higher education (done mainly by universities), to a model, which defines a new role of the universities within the knowledge society and economy in Europe [18] . This corresponds to the lack of enough state funding for university research and scientific equipment.
- Lack of youth staff. As a result from economical situation in Bulgaria and the small budget for the universities, young people are not motivated to continue their education as $\mathrm{PhD}$ students, researchers or teaching assistants at the universities. The permanent staff of the FMI is mainly from people over 45 years and the part of the young people under 35 years at the FMI presently is less than $15 \%$ of the staff and tend to decrease, because young people prefer to work at industry.

- Lack of stable and multiple bridges between research, development, education and training. Such bridges are a powerful mean for building a large community of researchers and improving quality of education.

- Lack of traditions in university-industry-government cooperation. Both universities and industry in Bulgaria could hardly build a strong cooperation in a short period of time although the government considers the ICT sector as an upper priority sector and a driver for development of Bulgarian industry and Knowledge Economy [10].

- Fragmented nature of research activities and the dispersal and not effective use of limited resources. FMI researchers have established a large network of partners at individual level. The large network of partners is, however, still not effectively harnessed for strengthening the research capacity of FMI. The individual partnerships of researchers seldom grow to institutional ones or a long-term collaboration. In addition, there is still dispersed project management expertise.

This paper describes a model for strengthening the research capacity of FMI, especially the one in the area of Software Engineering. The paper is organized as follows: Section 2 presents some known models and programs for strengthening the university capacity like Model of Research University, Model of Entrepreneurial University and several European initiatives; Section 3 introduces Sofia University and main research topics in the field of Software Engineering. Section 4 presents case study of successful industry-university cooperation with the focus on outcomes; Section 5 concludes the paper with information about upcoming European project for strengthening the research capacity of FMI and some open issues common for New Member States. 


\section{MODELS FOR STRENGTHENNING THE UNIVERSITY RESEARCH CAPACITY}

\subsection{Research University}

The model of Research University could be considered as among the most successful models for building research capacity in universities. While most of European universities, especially ones in the NMS, try to integrate education, research and innovation at a MSc and PhD level, many of the American research universities target the BSc level as well [8]. The research universities aim to make the baccalaureate experience an inseparable part of an integrated whole. Universities need to take advantage of the immense resources of their graduate and research programs to strengthen the quality of undergraduate education. Some research faculties might find new stimulation and new creativity in contact with bright, imaginative, and eager baccalaureate students, and graduate students would benefit from integrating their research and teaching experiences. In this respect the research universities are very different from small colleges, and they can offer a learning environment which is not typical for the small colleges and non-research universities. The baccalaureate student who studies in such environment develops his or her own research capabilities. The research universities could be both studentcentered and research-centered through a synergistic system in which faculty and students are learners and researchers, whose interactions make for a healthy and flourishing intellectual atmosphere.

Since the research universities commit to create new knowledge, they consider research capability as a primary qualification for appointment and promotion, and they are very proud of having world-class scholars among their staff. The America's research universities typically have an international orientation - they attract students, particularly at the graduate level, from many parts of the world, thereby adding valued dimensions of diversity to the community. The international graduate students often become teaching assistants, so their presence becomes a part of the undergraduate experience. And many research universities offer an array of interdisciplinary programs seldom available in smaller institutions. The graduates of these programs make the names of the American research universities recognized and respected throughout the world.

The concept of integrated education at a research university requires restructuring both the pedagogical and the management aspects of the university.

\subsection{Entrepreneurial University}

Another model is provided by the framework of "Entrepreneurial University" defined by Clark [13]. The main characteristic of such university is that it "understands the commercial value of knowledge". Clark identifies five elements that constitute the irreducible minimum of entrepreneurial actions for an entrepreneurial university. The degree of implementation of each of these actions provides some good indicators for successful transformation of a university towards the framework of an entrepreneurial university. These actions are:

- strengthening the steering core;

- expanding the developmental periphery;

- diversifying the funding base;

- $\quad$ stimulating the academic heartland;
- integrating the entrepreneurial culture.

In order to overcome the above mentioned problems, FMI is implementing a prototype of a university system combining the characteristics of both models $[37,38]$.

\subsection{European Programs for Strengthening Research Capacity in the New Member States}

The Lisbon strategy and its objective to make Europe the most competitive and dynamic knowledge-based economy in the world led to important policy initiatives [16]. One of them aimed at refocusing the European and national budgets on research and innovation, as stated by the Barcelona European Council and reach a level of $3 \%$ of GDP [17]. The Kok's Report [19] reconfirmed that Europe's future economic development would depend on its ability to create and grow high value, innovative and research-based sectors capable of competing with the best in the world. Among the main measures for achieving the Lisbon goals, Kok's report emphasizes that Europe needs to build a creative interaction between universities, scientists and researchers on the one hand and industry and commerce on the other, which drives technology transfer and innovation, being necessarily rooted in the close physical location of universities and companies". In addition, increased efforts should be mobilised at national and EU level by all concerned stakeholders to promote technological initiatives based on Europe-wide public-private partnerships.

EC very clearly recognized the role of the universities in building Europe of Knowledge [18].The commission aims at increasing universities' excellence in research and teaching. The European universities have to identify the areas in which different universities have attained some excellence essential for Europe and to concentrate funding on them to support academic research. The commission supports not only intra-European academic mobility, but also mobility between universities and industry, thus opening up new career opportunities for young researchers. The EC reports also that the number of young technological (spin-off) companies created by universities has been on the rise in Europe. Their average density nevertheless is far smaller than it is around the American campuses. A major obstacle to better application of university research results is the way intellectual property issues are handled in Europe. In addition, European universities do not have well-developed structures for managing research results.

Another important measure is to open up universities to the outside world and increase their international attractiveness thus preparing them to a broader international competition, especially with the American universities which attract the best talents from all over the world. It is reported that the European universities host almost as many foreign students as the American universities, in proportion they attract fewer top-level students and a smaller proportion of researchers. This means that the learning and research environment offered by the European universities is less attractive. The regions of the EU are supposed to play a very important role through the development of technology centres, science parks, and other cooperation structures between the business sector and the universities, and thus - to catalyze development of university regional development strategies and stimulate regional networking of universities. 
The EC considers the universities as motors of the new, knowledge-based paradigm but clearly states that they are not in a position to deliver their full potential contribution to the relaunched Lisbon Strategy [20]. The main conclusion is that "Europe must strengthen the three poles of its knowledge triangle: education, research and innovation. Universities are essential in all three. Investing more and better in the modernisation and quality of universities is a direct investment in the future of Europe and Europeans."

The Seventh Framework Programme (FP7) [24] tries to integrate all EU research-related initiatives in order to build the "knowledge triangle" - research, education and innovation which is a core factor in European efforts to meet the ambitious Lisbon goals [22]. The FP7 aims at establishing horizontal links with the new Competitiveness and Innovation Framework Programme (CIP), Education and Training programmes, and Structural and Cohesion Funds for regional convergence and competitiveness. It is also a key pillar for the European Research Area (ERA). European Technology Platforms (ETPs) [23] help industrial and academic research communities in specific technology fields to co-ordinate their research and tailor it to a common strategic research agenda (SRA), which sets out research \& development (R\&D) goals, time frames and action plans for technological advances that are relevant to industry and society [23]. SRA's aim is to mobilise a critical mass of national and European public and private resources. ETPs help industry and academia to better structure and co-ordinate their research in order to build links between the various elements of the innovation process.

The European Institute for Technology (EIT) is considered as an important step to fill the existing gap between higher education, research and innovation, together with other actions that enhance networking and synergies between excellent research and innovation communities in Europe [21].

Europe does not fully exploit its research potential, in particular in less advanced regions remote from the European core of research and industrial development. The FP7 Capacities Work Programme (Research Potential) aims at "establishing conditions that will allow research entities in these regions whether in the public or private sector - to exploit their research potential, thus contributing to regional development while taking advantage of the knowledge and experience existing in other regions of Europe. Hence this action will help to fully realise the European Research Area (ERA) within the enlarged Union" [25]. The commission aims at stimulating the realisation of the full research potential of the enlarged European Union by unlocking and developing the research potential in the EU's "convergence regions" and outermost regions, and helping to strengthen the capacities of their researchers to successfully participate in research activities at EU level and to provide support for:

- Trans-national two-way secondments of research staff in the convergence regions;

- The acquisition and development of research equipment in selected centres;

- The organisation of workshops and conferences to facilitate knowledge transfer;

- 'Evaluation facilities' for research centres in the 'Convergence regions' to obtain an international independent expert evaluation of their research quality and infrastructures.
Some barriers for implementing the Lisbon strategy that were reported in the above mentioned documents are:

- EU suffers from under-investment in human capital, especially in higher education;

- There is a chronic shortage of skilled ICT professionals in the "knowledge intensive sectors" - the demand for such specialists is expected to exceed supply by around $12 \%$ per year over the coming years;

- There is a substantial gap of 1.2 million R\&D staff, including 700,000 researchers;

- There is observed a clear process of decreasing the number of math, science and technology graduates in the EU and the commission defined a policy for increasing such graduates with $15 \%$ by 2010 ;

- EU still produces more science graduates than the US, but it has significantly fewer researchers in the labour market;

- There is a clear process of "brain drain" - more than 85,000 EU-born science and engineering employees currently work in the US;

In order to overcome some of the above mentioned challenges and build Europe of Knowledge, EC defined a new strategy for integrating the efforts and resources from FP7, CIP, European Technology Platforms and European Institute of Technology, Risk-sharing Financial Facility, Regions of Knowledge (Europe INNOVA Initiative), Structural Funds, LLL Program, national RTD and innovation programs.

The NMS have some specific problems on their way to implementing the Lisbon strategy, such as:

- The NMS keep loosing their human capacity and great investments in education (e.g. about 1 million of Bulgarian population moved abroad during the last 15 years);

- There are many cases of "brain-waste" for NMS and, respectively, for EU: e.g. a former NMS researcher working as a plumber in the US or in the EU;

- By February 2002, 14\% of the Marie Curie fellowship holders from NMS moved to the EU and only $0.5 \%$ of fellowship holders from the EU moved back to their countries;

- An open EU market for recruitment of researchers and ICT specialists is established before the complete Europe of Knowledge Ecosystem is built [EC, EraMore]. As a result - a new wave of brain-drain is expected.

- The EC keeps the tendency of building the EU RTD and innovation capacity in tiers, i.e. most of the NMS, especially the ones in SEE, would be certainly positioned in its RTD and innovation periphery.

- Some recent studies draw attention to the emergence of internal brain drain as a rising concern, namely the 
domestic 'drain' of intellectuals out of academia and science and into other occupations altogether [31]

Andrea, A Czech student, says 'You just can't compare our infrastructures or the investments we make in the education and scientific sectors with that of other European countries". But the students of today might be the scientists of tomorrow...." [33].

Bulgarian students are among the largest SEE student populations in many European countries, and between 1990 and 1992 around 40,000 Bulgarian scientists emigrated to the U.K., Germany, France and Ireland with the intention of settling permanently [29]. In addition, around 50,000 Bulgarian citizens leave the country annually

Howard Moore, Director, ROSTE, UNESCO expresses his opinion: "The countries of South-East Europe share some common problems to a greater or lesser extent - low investment in science, inadequate infrastructure in terms of research equipment; libraries, low industrial base and therefore very limited private sector involvement in science, and those issues lead to the chronic brain drain" [32]. Moore points out also that "Brain drain does indeed remain a chronic problem, although firm statistics are hard to come by. Brain drain is not just brought about by low salaries. People also need modern equipment, access to scientific literature and to be able to exchange information and experience" and "The Seventh EU Framework Programme beginning in late 2006 will grant access to scientists from Southeast Europe wishing to participate in the Union's scientific programmes. Often, however, what these scientists lack is the experience in making grant applications, which seem to get more and more complicated by the year. Equally, science managers in these countries lack experience in running international research programmes. Here, we hope in the near future to hold a training workshop on the subject for the benefit of individuals in Southeast Europe" [35].

The above said rises the question: "Are the NMS considered by the EC as the main suppliers of high-skilled workers and researchers for EU-15?" Obviously not, but the efforts of the EC is not enough to impose implementation of some well known models and policies that proved they were leading to best practice results. There are several well recognized models for turning the brain drain into brain gain and brain circulation [9], especially ones in the area of software industry in Ireland, India, Israel and other countries [5 ]. Some recent studies show that "While the brain drain has long been viewed as detrimental to poor country's growth potential, recent economic research has emphasized that alongside positive feedback effects arising from skilled migrants' participation to business networks, one also has to consider the effect of migration prospects on human capital building in source countries. This new literature suggests that a limited degree of skilled emigration could be beneficial for growth and development. Empirical research shows that this is indeed the case for a limited number of large, intermediateincome developing countries. For the vast majority of poor and small developing countries, however, current skilled emigration rates are most certainly well beyond any sustainable threshold level of brain drain" [15]..

There should be clear national and regional policies for substantial investments in building appropriate research and innovation ecosystem in NMS, including in the countries from
South-Eastern Europe. However bringing back high qualified specialists to the sending countries has been successful in a small number of countries, e.g. Ireland, and since the 1980s in some Newly Industrialized countries, namely Singapore, Taiwan, India, and China [Breinbouer]. It is pointed out that since the mobility of high qualified specialists "is highly complex and therefore successful policies must take a multidimensional approach on an individual, institutional, regional, national, supra-national and global level".

\section{THE CASE OF SOFIA UNIVERSITY}

\subsection{Background}

Sofia University (SU) is the leading research and teaching university of Bulgaria, which is also an important resource bank of researchers for Bulgaria. Established more than a century ago, in the lecture halls of SU thousands of young people have studied Mathematics, Biology, Chemistry, Physics, Geology, Informatics, Economics, Law, Philology, etc. and afterwards have incorporated their professional skills into the building up of modern Bulgaria. The Faculty of Mathematics and Informatics (FMI) of SU has been developed as a leading institution in the field of Information and Communication Technologies (ICT) research and higher education in the last decades. With more than 150 researchers and more than around 2500 students (BSc, MSc and $\mathrm{PhD}$ ), FMI is among the largest departments of Sofia university. The Faculty has been involved in more than 30 ICT related projects under the EC RTD Framework Programmes, several projects funded by national funds, as well as in projects funded by World Bank, PHARE and PHARE TEMPUS, Leonardo, Socrates, etc. These projects aimed at improving the quality of university research and training and to pave the way towards entering the European Research Area (ERA), the European Space of Higher Education and the European Area of Lifelong Learning. Within these projects FMI has been developed as one of the most promising research centres in Bulgaria in the area of ICT. The main achievements of its researchers are in the areas of TechnologyEnhanced Learning, Software and Services, Networked Enterprises, Intelligent Content and Semantics. In these fields FMI has achieved some European wide reputation and substantial research outcomes, the FMI researchers have published more than 200 papers in well known journals and conference proceedings, and many contacts with leading EU and international research institutions have been established. A number of successful activities have focused also on collaboration with other stakeholders like public bodies, industry, NGOs, etc. FMI has been recognised as a leading ICT centre in South East Europe (SEE), where it has built good partnerships, as well. A good indicator for the above statements is that FMI hosted the Third Balkan Conference in Informatics - BCI2007 [6].

In 1999 a Centre of Information Society Technology (CIST) associated with FMI was established in the frames of aTEMPUS PHARE Institutional Building Project. The main role of CIST was to become a centre of excellence and expertise in the field of Information Society Technology (IST) and to consolidate a critical mass of researchers, innovators and trainers who are able to spread out this expertise at institutional (FMI, SU), national and international level. The case of CIST was presented as a best practice case at the World Bank Knowledge Economy Forum in Helsinki [37]. CIST was chosen also as a best case in the Annual 
Report on the National Innovation Policy [MEE]. CIST has a leading role in promoting innovation, technology transfer and entrepreneurship through participating in EC funded projects and initiatives and several national and regional ones.

\subsection{Research in Software Engineering at Sofia University}

An internal project of FMI has been implemented in order to transform the Informatics curricula to current state of the art [Nikolov, Ilieva]. The re-designing the computing curriculum was done according to the ACM/IEEE guidelines started four years ago. Following the ACM/IEEE CC2005 series recommendations [2] FMI has developed the BSc programs in: Computer Science [4], Software Engineering [3] and Information Systems [1]. The main aims were to introduce some well established curriculum standards and new style of teaching. The main challenge was how to satisfy recommendations of the ACM/IEEE Computing Curricula, the Bologna Declaration, and several European ICT curricula recommendations [11,12]. The real evaluation of our efforts is figures from the students' enrolment in last 3 years. A growing interest in Software engineering education is observed in Bulgaria - for example at Master level there is an increasing number of applicants in conditions of a constant annual enrolment. In addition the highest entry scores (in Sofia University we have entry exam at Bachelor and Master Programs) in FMI are for Software Engineering specialty. For last academic year there are 86 applicants for MSc in Software education but we can educate only 40 because of the limited lecture halls, computer labs and teaching staff. The first year we offered BSc program in Software Engineering there were 40 places and 3 times more applicants.

As a natural consequence of all efforts of FMI related to the Software Engineering a new department, named Software Engineering, was established on March 1, 2007. However, the research in the area of Software Engineering had been run several years before official establishment of the department. The main priorities of research activities, defined by the department, are:

- Software development processes and methodologies. The members of the department have already had successful participation in European project named eXPERT in the field of agile methodologies [27]. During the project a training seminar on Personal Software Process [30] and Extreme Programming [7] agile methodology for the members of the eXPERT team was organised. The training was provided by the eXPERT project coordinator European Software Institute (ESI) - Spain. After the successful Bulgarian involvement some strong cooperation lines with ESI were established. Among the main project outcomes was the establishment of the Bulgarian branch of ESI - namely ESI-Bulgaria. In addition, as project follow up activities, a good cooperation of Sofia University and ESI-Bulgaria was established as well and some free training courses on Software Engineering were provided to a number of university lecturers. .Most of them successfully passed the course on CMMI and got professional certificates. The accumulated knowledge and expertise were exploited in designing and delivering several MSc courses at Sofia University..
- $\quad$ Component based software engineering. The research team of FMI got some good background in this area by participation in the FP5 project ECUA and by establishing strong cooperation lines with Malardalen University. The main accumulated expertise includes, among others, methods and models for description of non-functional properties of component architectures, such as reliability, formalization of requirements for application of built-in testing (according the SAVE CCM model), specification on applications development framework based on the SAVE CCM component model, etc. In addition, some educational materials were developed and embedded into some MSc courses, $\mathrm{A} \mathrm{PhD}$ thesis in the area of methods for component based architecture description was successfully defended and it gave ground for some state-of-the art graduate research in the filed of Aspect Oriented Built-in-Testing on Component Based Software Systems.

- $\quad$ Software services. This area of expertise was successfully developed as a result of the active involvement of some FMI researchers in the European technology Platform NESSI [36] activities. The university researchers, along with some representatives of Bulgarian software companies, participated in the NESSI working groups meetings and workshops aiming to define the European Strategic Research Agenda (SRA) in software services. The FMI researchers identified some of the most promising areas of further RTD activities, where the FMI team has built some capacity, such as: modelling, simulation, and behavioural analyses of services ecosystems, SOA applications development process, SOA testing. One of the PhD students is currently working on an approach for universal ontologybased services descriptions. Those descriptions should have characteristics such as semantically expressive, automatically comparable, flexible, editable, etc.

The process of identification of the main research topics of the FMI researchers were closely coordinated on an on-going basis with some representatives of the Bulgarian software industry, and. this cooperation is continuously evolving.

\section{A CASE STUDY OF INDUSTRY - SOFIA UNIVESRITY COOPERATION}

The implementation of the FP5 eXPERT project will be analysed as an example of fruitful university-industry cooperation.

\subsection{1 eXPERT project aims}

The aim of the eXPERT project is to provide the SMEs doing ebusiness and/or e-commerce a powerful approach for developing their software projects by facilitating all activities, which have crucial importance for a project success: development, management of time, changes, quality, customer relationships, and professional growth of the employees.

\section{The objectives of the eXPERT project are:}

- to define a lightweight approach for e-business and ecommerce software development based on the principles of eXtreme Programming (XP) and the Personal Software Process (PSP). Those principles were carefully selected in order to address the and without contradiction; 
- To use these approach in 7 pilot projects (two of which were in Bulgaria);

- To collect lessons learnt.

In addition the project expected to achieve the following main business results:

- to increase the productivity of small teams by $20 \%$,

- $\quad$ to reduce defect rates by $30 \%$,

- $\quad$ to reduce project costs by $15 \%$,

- to eliminate schedule delays and over costs.

Eleven partners took part in the project, whose roles were either to be "centres of expertise" or "member companies" associated to them:

- Member Companies (MC). They describe their needs according to the peculiarities of their organisations and the projects they develop, in order to make sure that the training and the subsequent experiments will be useful and interesting to them; apply eXPERT approach to their pilot project development and take part in analysing the lessons learnt from the experiments.

- Centres of Expertise (CE). They assess the needs of the MC in order to decide how to combine XP and PSP and on which aspects of the new approach to focus during the training and the experiments. In addition the EC have to support the associated MC during the whole period of experiment performance and analyse the experiment best practices.

Centre of IST, Sofia University played the role of a Centre of Expertise and two Bulgarian companies were involved as MC Nemetschek (www.nemetschek.bg) and Rila Solutions (www.rila.bg).

The main motivation for Sofia University to participate in the eXPERT project could be summarized as follows:

- To analyse the effects of implementation of the eXPERT approach for the software development by , combining the principles of eXtreme Programming (XP) and PSP, and observe some implemented solutions in different European SME's in terms of advantages, disadvantages, benefits, bottlenecks, etc;

- To analyse the typical needs and requirements of software development methodology in European SME's in order to allow them to implement more effective way of work, and to be more competitive in e-project developments in the European and world market;

- To disseminate the achieved results and conclusions to other European SME's and related to the subject interested parties (governments, consultant companies, software developers, service providers, etc.) through "Best practice CD-ROM", news, bulletins, seminars and other dissemination activities.

- To include the new methods and techniques in the curricula and training programmes for students and professionals who study software technologies and software engineering.

\subsection{2 eXPERT project activities}

As it was mentioned in the previous section, before starting the essential work a training seminar on PSP (1 day) and XP (4 days) was organised for all project partners - $\mathrm{CE}$ and $\mathrm{MC}$. The main aim was to provide the participants with good background knowledge in the methodologies, which would help them to define eXPERT as a meaningful and useful combination of practices originating from both sources. Sofia University, together with the other CE, defined the eXPERT approach, i.e. what it means, what it uses and how the application process runs. In parallel to the eXPERT approach a Framework for Analysis of the Experiments was defined, which described the process of conducting the experiments, including describtion of the baseline and the pilot projects, planning and organising the pilots, collecting data, preparing and conducting reviews and estimating review results. The SMEs defined and executed the Baseline and the Pilot Projects in the MC. Both type of projects had to develop the same or comparable software products. In the baseline projects the companies had to apply their traditional approaches, while in the pilot projects the the eXPERT methodology had to be used. During the execution of the experiments, the MCs, assisted by the CEs, collected the necessary indicators and defined the metrics to measure the success of the experiments. CEs made reviews of the pilot projects (3 reviews per project) and also analyzed them.

\subsection{3 eXPERT project outcomes}

A key success factor of the whole project was the establishment of a close collaboration between the partners, especially between the CEs and their MCs. The teamwork of the CEs with their MCs allowed the CEs to better understand the specifics of their Members' projects and to effectively support them in implementing and adjusting the eXPERT approach to their needs. The reviews of the experiments served as check points for the results achieved and difficulties encountered. The fact that they were made at relatively short periods prevented the pilot teams from deviating a lot from the project objectives.

The project objectives (theoretical and business) were successfully completed and results were reported [28]

\subsubsection{PhD students}

One of the Bulgarian companies hired a member of the eXPERT project team. Later on this employee became a PhD student at the university. He worked hard not only on practical experiments consisted of new methodology implementation but on some theoretical aspects and successfully developed and defended his $\mathrm{PhD}$ theses shortly after the project end. The topic of research was "Application of agile methodologies for software development in ISO certified companies". The main goals addressed were: to critically analyse the most popular contemporary agile methodologies, and to systematize in a procedure the necessary activities for selection of most appropriate agile methodology for a particular project. The study was based on the comparison matrices depending on specifics of the project, the company and other factors. It could be used as a guideline for decision making related to the software development process. The most valuable contribution of this $\mathrm{PhD}$ thesis was the detailed gap analyses and the 
recommendations for implementation the agile methodology in SMEs with certified process. The basic parameters for the gap analyses were selected and all the elements of certified process were covered. Another useful result was the identification of appropriate metrics for measurement of the achieved results of the agile methodology application in a software company. Based on the proposed metrics the analytical data were gathered and analysed.

Recently another PhD student started doing research on the agile methodology applications for component based systems and service oriented systems. By the focus on the methodologies and software processes, this work makes links with the other two research directions chosen by the department. The first directions of study were to analyze and summarize the agile practices and techniques and to propose a framework for evaluation of the applicability of a given set of practices. As a first step some set of good practices available for each phase of the software development life-cycle were identified. Counting the dependencies and the constraints between them was estimated the practices' compatibility. Secondly, the impact of several external factors, divided in three main categories - social, business and technological, was examined. The results from the analysis were used for evaluation of the selected set of practices against the other identified practices according to the internal dependencies between practices and particular external factors.

\subsubsection{Summer school}

During the eXPERT project implementation a summer school for the FMI teachers, PhD students, and developers.was organized. The lectures were delivered by experts from the university and industry who participated in the eXPERT project.

\subsubsection{New university courses and updated content of the existing ones}

As a result of the expertise and the experience gained during the project implementation a new course was developed and delivered for the students in the MSc program on Software Engineering at Sofia University. The course named "Advanced Software Engineering - Part 2" aimed to introduce to students the current state of the art in agile methodologies, including their main values and principles. The course covered, among others, the following topics: critical analyses of existing agile methodologies; Extreme Programming (XP) and best practices; planning, documenting and management of agile projects; tools for applying agile methodologies, etc. The lecturers used the eXPERT experience and lessons learnt for illustration of the new methodology.

As a natural outcome more then 5 papers were accepted and presented at prestigious international conferences.

\subsection{Other projects in Software Engineering}

The main results from the already finished projects in the area of Software Engineering implemented in close industry partnership, are summarized bellow:

- $\quad$ FP5 WG-EQUA project. In the frames of this project a methodology for description of software architecture was created. This methodology improves the existing architecture description languages with capability to formally describe non-functional characteristics (particularly reliability) of software systems. In addition, a classification of software wrappers was developed; A comparison of the existing ADLs was made and their advantages and disadvantages were defined. A formal definition of the properties of software architecture models (particularly scalability and compositionality) was proposed as well. The project gave birth of a $\mathrm{PhD}$ thesis which was successfully developed and defended 2006. A large number of MSc theses were developed and defended as well.

- FP5 Project DIOGEN. One of the main results of the project was the development of a ontology of Component-Based Software Engineering. That ontology was further used into the design of an abstract, simplified view of a training domain for COTS.

- $\quad$ FP6 project TENCompetence. Several FMI researchers and students, including $\mathrm{PhD}$ students, actively participated into the Technical Design \& Implementation of the Integrated TENCompetence System for life long competence development. All software implemented follows the principles of service oriented architecture and it is composed by reusable, standardized services.

It is obvious that FMI has a lot of strengths and weaknesses which need to be carefully analysed and put into a strategic framework for long-term growth and better integration into the EU research, innovation and education areas. Therefore, a proposal named "SISTER: Strengthening the IST research capacity of Sofia University "was developed and it was approved under the FP7 Capacities Work Programme[ 39]. The first project action line is dedicated to defining a Research, Technology Development and Innovation (RTDI) strategy for FMI for the period 2008-2013. The strategy will be based on a SWOT analysis of FMI research and innovation, the Bulgarian and SEE needs and the ICT research trends and challenges on European level. Within the project, the strategy will underpin the activities for further capacity building and strategic networking in the area of ICT, as well as on determining research areas for future projects under FP7 or other Community programmes.

The second action line of the project will be to support the present research collaboration of FMI in two ICT strategic areas Software and Services, and Intelligent Content and Semantics. Strengthening the PhD level of Software and Services research at FMI is between the main priorities of the SISTER project and this action would positively influence the BSc and MSc programs in Software Engineering as well. The cooperation with the Bulgarian and international ICT industry will be also strengthened for supporting the national strategy in ICT and Software Engineering.

\section{CONCLUSIONS}

The three year project SISTER will be effectively used for further capacity building at FMI in the area of ICT, especially in the area of Software Engineering. However, without substantial institutional and governmental support the efforts of FMI would have some limited impact. A lot of additional funding and developments should be planed for building appropriate research infrastructure in order to create a real research university ecosystem in the area of Software Engineering. Referring to the experience gained, some general conclusions related to a strategy 
for ICT capacity building in NMS, respectively - in Bulgaria, are formulated bellow.

Building educational, $R \& D$ and innovation infrastructure and human capacity in NMS could be considered as a separate EC action. It might include:

- Development of a strategy and action plan for a substantial improvement of the NMS infrastructure and human capacity in education, RTD and innovation, e.g. by using Structural Funds, EIB, other investment funds, VC (e.g. the Irish model);

- $\quad$ Stimulating outsourcing of RTD \& innovation activities from EU-15 to NMS, including building joint-ventures (following the similar model of the high-tech industry);

- $\quad$ Promoting usage of ICT for building virtual research and innovation labs based on the EC experience (e.g. in Collaborative Working Environments, Living Labs, eScience, eInfrastructure, eLearning, Networks of Excellence).

- $\quad$ Promoting a policy for building the European RTD and Innovation Ecosystem from the 'periphery' (NMS) towards EU-15. This strategy could be applied for instance while building the European Institute of Technology and the Knowledge Innovation Communities

- Promoting establishment of stronger mechanisms for technology transfer and knowledge (rather people) mobility between EU-15 and NMS;

- Promoting usage of ICT for establishment of a European wide network of virtual educational, research, innovation, technology transfer and business organisations. This organisations could span the network of EU born high-skilled experts working outside EU, and thus pave the way for their return back in EU (including in NMS);

- Stimulating research activities and entrepreneurial education at any level of education and training and lifting the barriers of students, teachers and researchers in the NMS for building their high-tech business startups;

- Launching an European initiative for university Software Engineering Curricula re-design and introducing programs and courses in Technology Entrepreneurship \& Innovation at all levels in NMS. Some measures in the area of ICT are:

- Implementing BSc Curricula standards (e.g. ACM/IEEE CC2001/CC2005 - BSc in CS, SE, IS);

- $\quad$ Designing MSc Programs linked with the EC ICT priorities and targeting the needs of the global ICT industry;

- Designing PhD programs related to the EC ICT priorities that open the opportunities for industry sponsored $\mathrm{PhDs}$.
- Developing of a model for internships in ICT industry.

- Promoting the concepts of "Research University" and "Entrepreneurial University" in NMS and launching European initiatives for their implementation.

\section{REFERENCES}

[1] ACM/AIS/AITP, Model Curriculum and Guidelines for Undergraduate Degree Programs in Information Systems, Association for Computing Machinery (ACM), Association for Information Systems (AIS) \& Association of Information Technology Professionals (AITP), 2002.

[2] ACM/IEEE, Computing Curricula 2005 - The Overview Report, ACM and the IEEE Computer Society, 2005.

[3] ACM/IEEE, Computing Software Engineering 2004, Curriculum Guidelines for Undergraduate Degree Programs in Software Engineering, Report, $A C M$ and the IEEE Computer Society, 2004.

[4] ACM/IEEE, Computing Curricula 2001, Computer Science, $A C M$ and the IEEE Computer Society, 2001.

[5] Arora, A., and A. Gambardella, eds.: From Underdogs to Tigers: The Rise and Growth of the Software Industry in Brazil, China, India, Ireland, and Israel, Oxford and New York: Oxford University Press, 2005.

[6] BCI2007, http://bci2007.uni-sofia.bg/

[7] Beck, K., Extreme Programming Explained: Embracing Change, Addison-Wesley, 1999

[8] Boyer Commission. Reinventing Undergraduate Education: A Blueprint of America's Research Universities, Technical Report, http://naples.cc.sunysb.edu/Pres/boyer.nsf/, 1998

[9] Breinbauer, A., Brain Drain - Brain Circulation or ... What Else Happens or Should Happen to the Brains Some Aspects of Qualified Person Mobility/Migration, FIW Working Paper $\mathrm{N}^{\circ} 004$, June 2007

[10] David, P., Foray, D. Economic Fundamentals of the Knowledge Society, Policy Futures In Education.An eJournal, 1(1) : Special Issue: Education and the Knowledge Economy, 2003.

[11] Carrier Space Curriculum Development Guidelines: New ICT Curricula for the $21^{\text {st }}$ Century, Designing Tomorrow's Education, http://www.career-space.com/, 2001.

[12] Carrier Space Job Profiles, http://www.career-space.com/, 2001.

[13] Clark, B. R.. Creating Entrepreneurial Universities, organisational pathways of transformation. Oxford: Pergamon, 1998.

[14] DAITS, http://www.daits.government.bg/index en.php

[15] Docquier, F. \& Rapoport, H, The Brain Drain, in: Stephen Durlauf, S. \& Blume., L, New Palgrave Dictionary of Economics (second edition), to be published in May, 2008

[16] EC (2000a), Lisbon European Council, Presidency Conclusions, http://ue.eu.int/Newsroom/ 
[17] EC (2002c), Presidency Conclusions, Barcelona European Council, http://ec.europa.eu/invest-inresearch/pdf/download_en/barcelona_european_council.pdf

[18] EC, The role of the universities in the Europe of knowledge, $\operatorname{COM}(2003)$ 58, Brussels, 05.02.2003

[19] EC (2004), Facing the challenge, The Lisbon strategy for growth and employment, Report from the High Level Group chaired by Wim Kok, ISBN 92-894-7054-2, http://europa.eu.int/comm/lisbon_strategy/index_en.html

[20] EC, Mobilising the brainpower of Europe: enabling universities to make their full contribution to the Lisbon Strategy, $\operatorname{COM}(2005) 152$ final, http://europa.eu.int/eur-lex/lex/ LexUriServ/site/en/com/2005/com2005_0152en01.pdf, 2005

[21] EC, European Institute of Technology, Leaflet, 2006, http: //ec.europa.eu/education/policies/educ/eit/doc/flyer_en.pdf

[22] EC (2006a), Amended proposal for a Decision of the Parliament and the Council concerning the $7^{\text {th }}$ framework programme of the European Community for research, technological development and demonstration activities (2007-2013), COM(2006) 364final

[23] EC (2006b), Overview of European Technology Platforms in $I C T$, Directorate-General Information Society and Media, Unit C2-Strategy for ICT Research and Development

[24] EC, Seventh Research Framework Programme (FP7), http://cordis.europa.eu/fp7/

[25] EC, FP7 Capacities Work Programme: Research Potential, (European Commission C(2007)5759 of 29 November 2007

[26] EC, ERA-MORE, http://ec.europa.eu/eracareers/

[27] eXPERT project, IST-2001-34488, Deliverable D1, 2001

[28] eXPERT project, IST-2001-34488, Deliverable D12 Dissemination, 2002

[29] Horvat, V, Brain Drain. Threat to Successful Transition in South East Europe?, Southeast European Politics, Vol. V, No. 1, 2004, pp 76-93

[30] Humphrey, W., Introduction to the Personal Software Process, Addison-Wesley, 1997
[31] Jałowiecki, B. \& Gorzelak, G., Brain Drain, Brain Gain, and Mobility: Theories and Prospective Methods, Higher Education in Europe, Special Issue on "Brain Drain and the Academic and Intellectual Labour Market in South-East Europe", Vol. XXIX, No. 3, 2004

[32] Kane, E, Proceedinggs of the Conference "The European Charter for Researchers and the Code of Conduct for their Recruitment, Conference Held under the UK's Presidency of the European Union, 8-9 September, 2005

[33] La Commare, I, Youth Brain Drain from the East, in: Cafebabel, Who's Afraid from the Brain Drain?, http://www.cafebabel.com/en/dossier.asp?id=204

[34] MEE, Annual Report for the state and development of the National Policy in the area of Innovation, Sofia, 2006

[35] Moore, H., Making the European Research Area truly panEuropean, A World of Science, Vol. 3., No.3, JulySeptember, 2005

[36] NESSI Technology platform, http://www.nessieurope.eu/Nessi/

[37] Nikolov, R. (2003), Towards Education and Training as a Meta-Industry, World Bank Knowledge Economy Forum, Helsinki, March 25-28, http://www.worldbank.org/eca/helsinki/torstai/ilpotapio/bulg aria/Bulgaria case study.doc, http://www.worldbank.org/eca/helsinki/torstai/ilpotapio/bulg aria/ie.html

[38] Nikolov, R., Ilieva, S. (2007), Building a Research University Ecosystem: the Case of Software Engineering Education at Sofia University, ESEC/FSE 2007 Conference, Widened Software Engineering track, Dubrovnik, 3-7 September

[39] SISTER project, Description of the work, internal document, 2008 